\title{
LO ANIMAL COMO LUGAR DE RESISTENCIA ANTE LA TRAMA SACRIFICIAL DE LA FILOSOFÍA ${ }^{1}$
}

\author{
AnAhí Gabriela GonZÁlez ${ }^{2}$ \\ Consejo Nacional de Investigaciones Científicas y Tecnológicas \\ Universidad Nacional de San Martín - Université de Paris 8 \\ http://dx.doi.org/10.15304/ag.38.1.4563
}

\section{Resumen}

El presente artículo analiza las posibilidades de resistencia ético-políticas que habilitan la deconstrucción de la dicotomía humano-animal. Se argumenta que el concepto de carnofalogocentrismo visibiliza las taxonomías de subordinación que constituyen la matriz de inteligibilidad de las estructuras de dominación modernas, al establecer nexos oblicuos entre binomios jerarquizados (animal/humano, mujer/hombre, emoción/logos). En este sentido, se sostiene que la deconstrucción interseccional de la maquinaria carno-falogocéntrica posibilita la apertura a otros modos de comunidad en los que no hay una propiedad que delimite un espacio de lo común, sino la promesa de construir otros modos de existir con y entre los otros en la diferencia radical.

Palabras clave: animalidad, carno-falogocentrismo, deconstrucción, alteridad, ecofeminismo.

\section{Abstract}

This article analyzes the possibilities of ethical-political resistance that enables the deconstruction of the human-animal dichotomy. It is argued that the concept of carno-phallogocentrisme makes visible the taxonomies of subordination that constitute the intelligibility

Recibido: 19/01/2018. Aceptado: 29/05/2018.

${ }^{1}$ Esta investigación fue financiada con la Beca Doctoral del CONICET (Consejo Nacional de Investigaciones Científicas y Técnicas).

${ }^{2}$ Becaria del Consejo Nacional de Investigaciones Científicas y Técnicas (CONICET). Doctoranda en Filosofía en cotutela entre la Université Paris 8 y la Universidad Nacional de San Martín. Licenciada en Filosofía por la Universidad Nacional de San Juan. Actualmente es integrante del Instituto Latinoamericano de Estudios Críticos Animales y codirectora de la Revista Latinoamericana de Estudios Críticos Animales. Email: anahigabrielagonzalez@ gmail.com 
matrix of modern structures of domination, by establishing oblique connections between dichotomous pairs (animal/human, female/male, emotion/logos). In this sense, it is argued that the intersectional deconstruction of the carno-phallogocentric machinery makes possible the opening to other modes of community in which there is no property that delimits a space of the common, but the promise to build other ways to exist with and between the others in the radical difference.

Keywords: animality, carno-phallogocentrism, deconstruction, alterity, ecofeminism.

\section{Introducción}

Los Estudios Críticos Animales han emprendido un camino que problematiza las normas regulatorias en las que el binomio humano-animal sostiene múltiples jerarquías y exclusiones sobre los vivientes. Diversos autores se han abocado, en mayor o menor medida, a desentrañar los modos en que lo humano se ha determinado por la sujeción y el sacrificio de aquellos clasificados como animales, desmantelando la ratio especista que rige la organización, la explotación y el disciplinamiento de los cuerpos no humanos. De allí que "la cuestión animal" sea una clave estratégica para deconstruir el discurso de la metafísica de la presencia, como así también un problema político en relación con las dinámicas de gestión y administración de la vida. Deconstruir la dicotomía humano-animal es entonces un desafío ineludible para el pensar contemporáneo, puesto que dicho binomio consolida una política (y una ontología) racista, falocéntrica, cisheterosexual, colonial y especista que perpetúa una labor de dar muerte a aquellos otros no codificados como "humanos" (González, 2016, p. 126).

Asimismo, la crítica a los conceptos de "Sujeto" y de "Hombre", inaugurada por Friedrich Nietzsche, impulsó la necesidad no sólo de desmontar esa distribución sobre los vivientes, sino también de producir "otros sentidos que den cuenta y potencien los ensamblajes humano-animal: modos de relación, del afecto, de la supervivencia, [...] que escenifiquen esa 'justicia interespecie' de la que habla Donna Haraway: modos del vivir y morir 'con' otros cuerpos, componiendo sentidos 'no-antropocéntricos y no-antropomórficos'” de los lugares vividos y de los modos de experiencia” (Giorgi, 2017, p. 14). Estas perspectivas intentan imaginar éticas y políticas animalistas que conciban la justicia en clave hospitalaria a las formas de vida - en su singularidad - a fin de abrir modos de coexistencia con los vivientes no humanos. Conceptos como el animot de Jacques Derrida (2008a) las "especies compañeras" de Donna Haraway (2008), el "devenir-animal” de Gilles Deleuze y Felix Guattari (2012), así como la re-lectura propuesta por Rosi Braidotti (2005), dan cuenta del desafío del pensar actual ante la divisa de imaginar "la radical alteridad de cualquier forma de vida" (Fleisner, 2017, p. 116). 
En este marco, el presente artículo intenta pensar posibilidades de resistencia ético-políticas ante los regímenes carnofalogocéntricos actuales, con el propósito de habilitar una comunidad de existentes que desplace al Hombre, en tanto fábula normativa, del eje del pensar occidental. En particular, la noción de carno-falogocentrismo (Derrida, 2005) da cuenta de las taxonomías de subordinación que constituyen la matriz de inteligibilidad de las estructuras de dominación modernas, al establecer nexos oblicuos entre binomios jerarquizados (animal/humano, mujer/hombre, emoción/logos). Por ello, se argumenta que esta perspectiva crítica permite visibilizar la conexión estructural de dispositivos de poder enlazados, donde la categoría de "especie" resulta clave para desmantelar las dinámicas de marginación de acuerdo al sexo/género, a la clase, a la raza, entre otras. Consecuentemente, la deconstrucción interseccional de la maquinaria carno-falogocéntrica habilitaría un pensamiento de lo comunitario como apertura a las singularidades vivientes, allí donde se deconstruye la lógica sacrificial que establece cortes sobre la base de los cuerpos que importan y de los que pueden matarse.

En primer lugar, se comenzará por argumentar la relevancia que posee el concepto de carno-falogocentrismo para visibilizar la distribución jerarquizante sobre lo viviente que sostiene un entramado de dominación, explotación y sujeción de diversas formas de vida animalizadas y/o feminizadas. En segundo lugar, se afirma que dicho concepto permite realizar una lectura crítica de la noción de biopolítica al dar cuenta de los modos de hacer morir a los vivientes, en una ontología principalmente masculina, humana, especista y logocéntrica. Finalmente, se interroga si una "ética del cuidado", pensada desde las coordenadas de la hospitalidad, habilita otros modos de ser-con los vivientes que no supongan los dispositivos especistas del usufructo y el sacrificio.

\section{Carno-falogocentrismo}

¿Qué sería del logocentrismo, de los grandes sistemas filosóficos, del orden del mundo en general, si la piedra sobre la que han fundado su iglesia se hiciera añicos?

¿Si un día se supiera que el proyecto logocéntrico siempre habría sido, inconfesablemente, el de fundar el falocentrismo, el de asegurar al orden masculino una razón igual a la historia de sí misma?

Hélène Cixous (1995, p. 16)

El problema de nuestra relación con los animales es situado por Jacques Derrida en una perspectiva interseccional, en el marco de su polémica con 
el falogocentrismo occidental. El autor, al formular su crítica hacia la metafísica tradicional en términos de carno-falogocentrismo, vincula la disponibilidad de la vida de los animales al privilegio de la Razón y al dominio masculino. En otros términos, Derrida plantea que existe una "configuración a la vez sistemática y jerárquica" (2010, p. 51) que ubica en la cima al soberano (amo, rey, hombre, marido, padre: la ipseidad misma) y debajo, sometidos y a su servicio, al esclavo, la bestia, la mujer y el niño. De ahí que la "cuestión del animal" constituya "un hilo conductor indispensable para leer a los filósofos y acceder a una especie de «arquitectónica» secreta en la construcción, por consiguiente, en la deconstrucción de un dispositivo discursivo, de una coherencia, si no de un sistema" (Derrida, 2008a, p. 127). Igualmente, el filósofo sostiene que "la deconstrucción del «logocentrismo" ha tenido necesariamente que desplegarse a través de los años en la deconstrucción del «falogocentrismo" y luego del "carnofalogocentrismo»" (2008a, p. 125).

En primer lugar, el logocentrismo indica que la tradición filosófica occidental establece un arkhé fundacional que estructura la realidad en su totalidad, al postularse como principio de referencia de lo existente. El logos se ubica así en el lugar central, como razón y medida de todo lo que es. En compañía de Plumwood (1993) podemos sostener que la "erección" de la Razón como marcador de superioridad ha supuesto la simultanea subordinación de aquellas corporalidades e inclinaciones ubicadas en el lugar de lo irracional. En este sentido, en sus primeros escritos, Derrida argumentó que el logocentrismo supone la devaluación de la escritura frente a la voz: esta última indica la voz del padre (el logos), que establece la medida, la norma, la ley, mientras la escritura escapa al control total del sujeto soberano $^{3}$. En sus últimos escritos sobre la cuestión animal, el filósofo indica que el logocentrismo, al suponer una devaluación de lo material frente a lo espiritual, es una tesis sobre el animal privado de logos, esto es, sobre el animal "privado de poder-tener el logos: tesis, posición o presuposición que se mantiene desde Descartes hasta Kant, Lévinas y Lacan" (Derrida, 2008, p. 43). Por consiguiente, el logocentrismo es un eje constitutivo de la inferiorización de los animales y de las mujeres, las cuales han sido identificadas con lo emocional y lo pasional, en oposición a la esfera del intelecto y de la Razón. Si la historia de la filosofía se caracteriza por una fuerte des-

\footnotetext{
${ }^{3}$ Como es sabido, el filósofo ha analizado de qué modo en la historia del pensamiento se plantea una relación directa y natural entre la voz (phóne) y el pensamiento (logos), mientras la escritura ocupa un papel totalmente secundario y derivado. Véase: Derrida (2008b).
} 
valorización del cuerpo y de lo material frente a lo racional y lo espiritual, para desplazar el discurso antropocéntrico es preciso desmontar el lugar fundacional y normalizador que posee el Logos en la tradición occidental.

En segundo lugar, el falocentrismo puede definirse como la identificación del sujeto con lo humano-masculino. Existe una unidad indisociable (Derrida, 1989) entre el logocentrismo (caracterizado por su privilegio de la presencia sobre la ausencia y de la razón frente a la corporalidad) y el falocentrismo que ubica a la mujer en una situación de subordinación frente al dispositivo masculino. El logos se ha instaurado como la voz masculina en tanto voz del dominio, en la medida en que, como señala Hélène Cixous: "Lo filosófico se construye a partir del sometimiento de la mujer. Subordinación de lo femenino al orden masculino que aparece como la condición del funcionamiento de la máquina" (1995, p. 16). La solidaridad entre falocentrismo y logocentrismo implica que la constitución del pensamiento según un esquema binario y jerárquico está en relación con "la" pareja, hombre/mujer, la cual asedia a los otros pares dicotómicos (Cixous, 1995, pp. 13-14). En palabras derridianas: "el falocentrismo es un logocentrismo. Así que trato de hacer aparecer esto un poco en todas partes, de manera que la cuestión de la mujer no es una cuestión entre otras en la deconstrucción" (González-Marín, 1986).

En tercer lugar, en la entrevista realizada por Jean-Luc Nancy, intitulada "Hay que comer o el cálculo del sujeto" (2005), Derrida se distancia de cierto antropocentrismo infundado, presente aún en las filosofías más críticas del humanismo, al poner de relieve que el sacrificio carnívoro es esencial para el esquema dominante de la subjetividad. El término carnocentrismo hace referencia a la relación entre "el sujeto" - el lugar del "quien"- y el sacrificio, entendiendo por este último "un lugar dejado libre en la estructura misma de esos discursos, que son también de las "culturas", para un matar [mise à mort] no-criminal” (Derrida, 2005, p. 164): con ingestión, incorporación o introyección del cadáver, operación que puede ser real o simbólica. La noción señala entonces la producción del sujeto humano a partir del poder dar muerte a los existentes animales, a la vez que hace referencia a la domesticación de todo aquello vinculado con la animalidad: para constituirnos como sujetos es necesario someter la vida, dominar nuestro cuerpo y nuestras pasiones en pos de la búsqueda del Bien y la Verdad. Es menester, en consecuencia, engarzar la deconstrucción del fono-falogocentrismo (ese discurso dominante que devalúa la mujer frente al Hombre y que prioriza la phóne sobre la escritura) con la deconstrucción de "la estructura sacrificial", por la cual el animal se encuentra a merced del sujeto soberano. 
A este respecto, Mónica Cragnolini ha señalado que existe un ejercicio de "virilidad carnívora" en el modo en que se han constituido la ética y la política (sobre todo, desde la época moderna) en torno a la figura del soberano (2012, p. 45). La "virilidad carnívora" definiría, según Derrida, el "esquema que domina el concepto de sujeto. Éste no se desea solamente señor y poseedor activo de la naturaleza. En nuestras culturas, él acepta el sacrificio y come de la carne" (p. 165). La exclusión de los no humanos del ámbito de la ética y de la política los arroja a la vulnerabilidad de una muerte no criminal, permitiendo su devoración simbólica y material en el régimen carnívoro, pretensión de devoración predominantemente machista. Pues, como indica el filósofo franco-argelino, la violencia infringida contra el animal se caracteriza por su carácter viril: "nadie podría negar que, en su forma fenoménica más general, desde la caza hasta la corrida, desde las mitologías hasta los mataderos, y salvo excepciones, es el macho el que la emprende con el animal" (2008, p. 125). En suma, el sometimiento de la animalidad es aquí la condición de posibilidad para la constitución de una forma de vida que se considera superior en términos de especie y de género, donde animales y mujeres son concebidos como "objetos apropiables" a disposición del sujeto masculino dominante, racional y soberano.

Esta tesis sobre la complicidad entre la centralidad del falo, la superioridad del logos y el sacrificio carnívoro tiene al menos tres implicancias. La primera es que las diferencias en el discurso occidental son organizadas de acuerdo a una arquitectura dual y oposicional: si el Hombre, en el discurso occidental, aparece como aquel que posee logos, lenguaje, conciencia, cultura y que, en suma, responde; el animal, al ser concebido como puro instinto sin posibilidad de respuesta, aparece exceptuado del ámbito éticopolítico. De manera similar, la mujer es conceptualizada desde la ausencia y la falta de todo aquello que es el Hombre y la masculinidad, mientras este constituye el lugar de la Razón y de la universalidad. La segunda implicancia es que el dualismo jerarquizante no es inocuo para los vínculos de sujeción, explotación y dominación que se establecen sobre los vivientes. El sometimiento sistemático de los animales y de los sujetos feminizados se basa en dicha dicotomía metafísica que es funcional a los modos (especistas y sexistas) de organización política. Finalmente, esta relación se caracteriza por ser un dominio soberano, devorador y vociferante: sacrificar al otro como ejercicio de afirmación mayestática sobre él ${ }^{4}$. Así pues, como afir-

${ }^{4}$ Se pregunta Derrida: “¿Será devoradora la soberanía? ¿Será su fuerza, su poder, su mayor fuerza, su poder absoluto, por esencia y siempre en última instancia, poder de 
ma Cragnolini: "ser sujeto implica, en alguna medida, poder convertir a lo otro, lo diferente, en parte de uno mismo, ya sea por asimilación, introyección o digestión" (2012, p. 47).

De modo que el sujeto propietario se constituye como tal en su ejercicio de virilidad apropiadora de la alteridad, lo cual se ha traducido en dispositivos de normalización, control, sometimiento y sacrificio de diversas corporalidades humanas y no-humanas.

\section{La presencia de los animales en el (eco)feminismo}

Si va a existir una ecojusticia multiespecie, que también pueda incluir diversidad de personas, ha llegado la hora de que las feministas ejerzan un liderazgo en la imaginación, en la teoría y en la acción para deshacer ambos lazos: de genealogía y parentesco, y de parentesco y especies. [...] Sea lo que sea que seamos, necesitamos hacer-con -convertirnos-en, componer-con- los "terranos". Donna Haraway (2016, p. 21)

La continuidad entre la objetivación y la explotación de los cuerpos de las mujeres, de los animales y de la naturaleza en su conjunto, ha sido indicada por diversas autoras ecofeministas ${ }^{5}$. Las formas de vida históricamente feminizadas y animalizadas son cuerpos apropiables por la maquinaria capitalista de las sociedades de normalización. En efecto, el sostenimiento de ese orden de poder es indisociable de la explotación de aquellas vidas que son consideradas objetos disponibles o mercantilizables, lo cual ha significado el encierro de los vivientes no humanos en lugares de confinamiento como granjas industriales, zoológicos, circos, laboratorios, entre otros, mientras las mujeres han sido recluidas al ámbito disciplinario del hogar. De ahí que Donna Haraway señale que, en la época del "patriarcado capitalista blanco", el Hombre moderno se erige como el objetivo lugar de la universalidad desde la cual puede controlar y utilizar "todo el cuerpo del mundo como un recurso para sus perversos proyectos" (1995, p. 341).

devoración [...]? [...] El lugar de la devoración [la oralidad, la boca, las fauces, los dientes, el gaznate, la glotis y la lengua] es también el lugar de lo que porta la voz, es el topos del portavoz, en una palabra, el lugar de la vociferación” (2010, p. 43).

${ }^{5} \mathrm{El}$ ecofeminismo es un amplio movimiento teórico y activista que se extiende desde mediados de la década de 1970 y que abarca una gran variedad de enfoques (Cfr. Warren, 2003). 
Si bien el ecofeminismo se ha diversificado en una amplia perspectiva de posturas teóricas y políticas, en todas pervive un intento de repensar las formas de vida más allá de toda dicotomía jerarquizante, la cual se patentiza como la matriz de inteligibilidad de las estructuras de dominación, sometimiento y exclusión que caracterizan la historia occidental. Así pues, se trata de una perspectiva que afirma luchar conjuntamente contra el sometimiento de las mujeres y la naturaleza, pero además en contra de la "lógica de la dominación" en todas sus formas (Cfr. Warren, 2003). Por ello, las diversas posturas convergen en que existen conexiones estructurales entre todas las formas de dominación: las distintas opresiones — racismo, especismo, colonialismo, heterosexismo, etc.- de "los «otros» del sujeto humanista" (Braidotti, 2009, p. 45), no sólo serían análogas sino que también se encontrarían vinculadas estructuralmente en términos históricos, empíricos y conceptuales.

En sintonía con la deconstrucción, podemos sostener que el carno-falogocentrismo visibiliza las escalas jerárquicas que organizan las relaciones de dominación, pues la diversidad de lo múltiple es ordenada conforme a un pensamiento dualista e identitario: las diferencias quedan subsumidas en pares dicotómicos y oposicionales, a saber, lo Mismo y lo Otro (varón/ mujer, hombre/animal, cultura/naturaleza, razón/emoción), que afirman la insistente supremacía de un polo en detrimento del otro. Los binomios jerarquizados colocan del lado del objeto o del "qué" a los cuerpos feminizados, racializados, disidentes, empobrecidos, a lo animal en nosotros mismos (el cuerpo, las emociones e inclinaciones) y a los vivientes no humanos, mientras que el lugar masculino, llamado por Val Plumwood la "perspectiva del Amo" (1993) o, para decirlo en palabras derridianas, la posición del "quién”, incluye a la cultura, la razón, el espíritu, lo universal. Las entidades colocadas en el lugar del "qué" no pueden adquirir la posición de "sujeto", mientras el lugar del "quien" indica la figura masculina del soberano o el ipse (Derrida, 2010) ${ }^{6}$.

Una de las ecofeministas que más impacto ha tenido es Carol Adams (2016), quien propone un enfoque interdisciplinar para analizar de qué modo el consumo de carne implica una política sexual y racial: las sociedades occidentales, particularmente a partir de la segunda mitad del siglo XX, han considerado el consumo de carne como un indicador de la masculini-

${ }^{6}$ Mónica Cragnolini señala, en su lectura del seminario La bestia y el soberano, que el "quién" y el "qué" definen lugares de la metafísica occidental que pueden ser pensados como el tradicional lugar del sujeto y del objeto (Cfr. Cragnolini, 2013). 
dad dominante y de la superioridad intelectual, mientras que los vegetales aparecen como el alimento privilegiado de las mujeres y de los sujetos racializados, pues, en el caso de estos últimos, su consumo es asociado a la falta de "desarrollo" intelectual de los pueblos no occidentales. ${ }^{7}$ En contraste con la ceguera de varios feminismos frente a la cuestión del antropocentrismo, Adams plantea que el patriarcado "es un sistema de género que está implícito en las relaciones humanas/animales" (2016, p. 46) puesto que la construcción de género señala instrucciones sobre cuáles son los alimentos adecuados para cada género. ${ }^{8}$ La virilidad está construida en la cultura occidental "por el acceso al consumo de carne y el control de otros cuerpos" (p. 46). Por eso, como señalábamos desde la deconstrucción, es posible hablar de una estructura sacrificial en la constitución del Sujeto, el cual no es sólo humano y racional, sino también heterosexual, masculino y carnívoro.

Este enlace histórico entre sexismo y especismo se configura a partir de un ciclo de objetivación, fragmentación y consumo que vincula la matanza animal y la violencia sexual en nuestra cultura. Según la autora esto ocurre a partir de la estructura del "referente ausente", categoría que indica que los cuerpos de animales y mujeres son tratados como objetos o propiedades, en lugar de ser considerados como singularidades vivientes en interrelación con el mundo que habitan. El animal sometido y sacrificado desaparece en la alusión neutralizada a "la carne" o "la comida", mientras que las mujeres aparecen como objetos naturalmente disponibles. De manera similar, Derrida da cuenta del proceso denegatorio del sacrificio animal, al señalar que su muerte nunca será pensada como asesinato, invisibilización que es enlazada a la institución violenta del "quien" como sujeto (Derrida, 2005).

${ }^{7}$ Carol Adams señala que el consumo de carne no es sólo índice de poder masculino sino también de racismo. Por eso acuña el término "política racial de la carne" (Cfr. Adams, 2016, pp. 102-105).

${ }^{8}$ De acuerdo con Adams en las sociedades occidentales la identificación humana masculina se obtiene, en parte, por la elección de alimentos, creando y recreando una experiencia de virilidad en varios lugares de identificación masculina, como determinados restaurantes, espacios de encuentro, en la caza, etc.

${ }^{9}$ A propósito de esa disociación entre el producto consumido y la violencia de sus vidas y sus muertes, Matthew Calarco indica que la "mera" carne que emerge del matadero nunca es solo carne para el consumo humano. En efecto, ésta se encuentra ligada a una singularidad viviente que podría "haberse desarrollado a lo largo de diferentes líneas conjuntas donde no estuviera restringida a vivir en una granja industrial para luego ser sacrificada" (Calarco, 2016, p. 44). Este viviente podría haber incluso resistido ferozmente a su asesinato, "un hecho que es más común en los mataderos y otros espacios de crueldad y confinamiento de lo que nos han llevado a creer" (p. 45). 
En palabras del autor: "Nadie puede ya negar con seriedad ni por mucho tiempo que los hombres hacen todo lo que pueden para disimular o para disimularse esta crueldad, para organizar a escala mundial el olvido [...] de esta violencia" (2008, p. 42).

$\mathrm{Si}$, de acuerdo con Adams, el género está implícito en las relaciones humanas/ animales, acaso sea porque el "patriarcado capitalista blanco" tiene como eje la "perspectiva del Amo" del sujeto masculino (cis-heterosexual) que se erige como el "propietario" de los cuerpos históricamente feminizados y/o animalizados. Al respecto, Paul B. Preciado ha indicado que el Renacimiento europeo, la Ilustración y la Revolución Industrial "reposan sobre la reducción de los cuerpos no blancos y de las mujeres al estatuto de animal y de todos ellos (esclavos, mujeres, animales) al estatuto de máquina (re-)productiva" (2014). Por un lado, los sujetos feminizados han sido apropiados, siendo considerados como "el lugar de la reproducción de la nación, de una nación de ciudadanos ideales que hacen eco del ideal de Hombre, y en general imaginados a disposición de este último" (Ávila, 2016, p. 52). En efecto, históricamente los sujetos varones se preservan de las tareas reproductivas y del cuidado, asignándoselas a los cuerpos feminizados. De manera que estos últimos, al ser asociados a lo sensible, material, natural, doméstico, entre otras instancias inferiorizadas, permanecen atados, tal como dictamina el régimen patriarcal, a las tareas no remuneradas de cuidado y de reproducción de la vida.

Por otro lado, de modo similar, los cuerpos de los animales son producidos como fuerza de trabajo, como objetos de experimentación científica, militar y cosmética o como elementos de entretenimiento para el ver, saber, poder, tener del sujeto soberano. En el seminario La bestia y el soberano Derrida recuerda que la subjetividad deviene referente y determinadora de la existencia a partir del poder, ver, querer, saber, tener y, en definitiva, del disponer de los Otros (2010). Por ende, si el dispositivo patriarcal de control reduce los sujetos construidos como "mujeres" a funciones domésticas y reproductivas, los animales, a su vez, son reproducidos, industrializados y comercializados para la satisfacción de supuestas necesidades "humanas", lo cual ha implicado el control sobre el sexo y los aparatos reproductivos de los “animales feminizados”. De ahí que Carol Adams señale que estas últimas constituyen los animales más oprimidos, pues su capacidad reproductiva es explotada para la producción de lácteos y huevos, entre otros productos, además de ser posteriormente asesinadas para el consumo humano: la "proteína feminizada" (Adams, 2017) implica entonces la explotación de los ciclos reproductivos de las así llamadas "hembras". 
En consecuencia, los cuerpos animalizados, feminizados (y también racializados), producidos en contraposición de lo humano-blanco-masculino, no son más que vidas apropiables y desechables en el circuito de producción "patriarcal capitalista blanco". Por ello Braidotti afirma que es posible hablar de "un vínculo estructural transversal en la posición de los sujetos no humanos corporizados que anteriormente se conocían como los «otros" del sujeto humanista” (2009, p. 145) ya que todos ellos constituyen cuerpos mercantilizables "en un modo global de explotación posthumana" (2009, p. 142).

\section{Biopolítica y soberanía}

Llegados a este punto, podemos señalar que la cuestión animal se ubica en la problematización de los cortes y articulaciones sobre la base de las vidas que importan, de aquellas que se "hacen vivir" (bios) frente a las que pueden matarse sin cometer asesinato (zoé). Sin embargo, la biopolítica contemporánea, si bien intenta ir más allá del cuestionamiento a la subjetividad moderna, no problematiza las fronteras basadas en la especie y el género. En otros términos: pasa por alto la especificidad de los cuerpos, en particular los procesos de explotación de los vivientes no humanos, así como invisibiliza la incardinación de sexo/género de las corporalidades.

El concepto de biopolítica, tal como es delineado por Michel Foucault, hace referencia a un modo fundamentalmente productivo del poder, cuyo objetivo es el fomento de la vida. ${ }^{10}$ Es en el marco del racismo de Estado que el biopoder puede ejercer la función de muerte. En efecto, el racismo introduce cortes y cesuras en el ámbito de la vida: los cortes entre lo que debe vivir y lo que debe morir (Foucault, 2008, p. 230), siendo esta la condición a partir de la cual se ejerce el derecho de matar: "En el continuum biológico de la especie humana, la aparición de las razas, su distinción, su jerarquía, la calificación de algunas como buenas y otras, al contrario, como inferiores, todo esto va a ser una manera de fragmentar el campo de lo biológico que el poder tomó a su cargo" (2008, p. 230). Por ende, el hacer vivir no sucede o sustituye al hacer morir, pues el poder mortífero está más "vivo" que nunca. La muerte no es una deriva ocasional del dispositivo: en la medi-

${ }^{10}$ El autor señala la transformación de la vieja operación de soberanía: mientras que esta última consistía en "hacer morir o dejar vivir", el biopoder se transforma en el principio de "hacer vivir o de rechazar hacia la muerte" (Foucault, 2005, p. 167). 
da en que este se aboca a la vida, no puede sino gestionar al mismo tiempo la muerte (Cfr. López, 2008).

Sin embargo, es necesario avizorar también de qué modo la biopolítica se basa en un pensamiento especista y androcéntrico que toma al Hombre como ratio y, al hacerlo, despliega un conjunto de prácticas de sometimiento no solamente hacia las poblaciones humanas sino también hacia la vida así llamada animal. Por ejemplo, en las granjas industriales a los animales se les imponen las mínimas condiciones de vida: los cálculos realizados alrededor de la ingesta nutricional, los niveles de iluminación, la distribución del espacio, etc. se encaminan hacia la maximización de la ganancia (Cfr. Wadiwel, 2002; Shukin, 2009). En otras palabras: se producen animales en confinamiento para disponibilidad del Hombre, los cuales son condenados a un régimen de explotación, sometimiento y sujeción que algunos autores, como indica Derrida, han comparado a los peores "genocidios" 11 . En suma, los animales son producidos y reproducidos para utilidad de ciertas formas de vida humanas: considérese la caza, la cría y la domesticación; el confinamiento, los circos y los jardines zoológicos; la explotación industrial y la experimentación con fines cosméticos, militares, y científicos, entre otros.

Asimismo, la diferencia sexual también se pasa por alto en el abordaje que realiza Foucault sobre las tecnologías de poder sobre la vida: como indica Braidotti, sus análisis se refieren a un sujeto "humano" desexualizado y general (1991, p. 87), pues el filósofo no ubica el cuerpo de la mujer como el sitio de una de las divisiones más operacionales en nuestra sociedad y, consecuentemente, como el lugar de una de las más persistentes formas de exclusión (Braidotti, 1991). Es menester recordar, siguiendo a Derrida (2010, p. 50), que el poder soberano sobre la vida y la muerte de los súbditos era correlativo al derecho del padre («un reyezuelo en su casa» dirá Hobbes) sobre su esposa e hijos y, a su vez, al derecho del hombre sobre las bestias. Asimismo, el trabajo de cuidado de los sujetos feminizados es

${ }^{11}$ En sus palabras "De la figura del genocidio no tendríamos que abusar ni liberarnos demasiado rápido. Porque ésta se complica aquí: la aniquilación de las especies, en efecto, estaría en marcha pero pasaría por la organización y la explotación de una supervivencia artificial, infernal, virtualmente interminable [...] Como si, en lugar de arrojar a un pueblo a los hornos crematorios y a las cámaras de gas, unos médicos o genetistas (por ejemplo, nazis) hubieran decidido organizar por inseminación artificial la superproducción y la generación asistida de judíos, cíngaros y homosexuales a los que, al ser cada vez más numerosos y estar mejor nutridos, se les habría destinado en un número siempre creciente al mismo infierno, el de la experimentación genética impuesta, el de la exterminación mediante el gas o el fuego" (Derrida, 2008a, p. 42). 
función de su subordinación histórica ya que este es apropiado sin ser asumido como trabajo, sino que es considerado como el lugar natural de dichos sujetos. El hogar es un espacio disciplinario de encierro y vigilancia orientado a la reproducción del sistema patriarcal de opresión, pues, como indica Rosa Rodríguez Magda, "la cárcel, la escuela, el cuartel... son espacios preferentemente masculinos, mientras que el ámbito de reclusión habitual para las mujeres sigue siendo el hogar" (2004, p. 100).

En la distribución normativa y jerárquica que se constituye sobre la base de vidas preservarles y vidas sacrificables, la comunidad política patentiza su carácter soberano. Carácter que es precisamente considerado como lo propio del Hombre en tanto principal referente de la Norma, de la Ley y del Logos (Braidotti, 2005, p. 102). En otros términos, es posible señalar que el soberano aparece casi siempre en la figura masculina del rey, del amo, del jefe, del padre de familia o del marido - de la ipseidad, en definitiva (Derrida, 2010, p. 92), y que por esa posición de poder se autoriza el control, la regulación y el sacrificio de los así producidos como Otros. En este punto Derrida recuerda la etimología común de las palabras ipse, "Amo" y "esposo" en las lenguas indoeuropeas: la palabra que significa "amo", potis, "en sánscrito patih (amo y esposo), en griego posis (esposo), compuesto despotês" (p. 93) se modifica al punto de llegar a significar «él mismo» ${ }^{12}$. Así pues, el soberano, en el sentido amplio del término, es aquel que tiene el derecho de ser reconocido como "sí mismo, el mismo, propiamente el mismo que sî" (p. 93).

En este sentido, la noción de carno-falogocentrismo visibiliza las políticas sacrificiales, de hacer morir a los vivientes en una ontología masculina, heterosexual, logocéntrica y especista. Esta visibilización desafía el cariz antropocéntrico y androcéntrico de la biopolítica dominante, al mostrar que los cortes y las rearticulaciones entre las vidas que "deben vivir" y las que, por el contrario, se arrojan a la muerte, tienen por referencia el esquema de subjetividad tematizado por Derrida - el de un humano varón, heterosexual, racional, adulto, blanco y propietario-, que es el eje desde el cual se jerarquiza a los vivientes en una gradación descendente desde lo verdaderamente humano hacia lo no-humano. Así pues, en lugar de preguntar sólo por el "racismo" como un modo de establecer cortes en el continuum biológico de la especie humana, tal como propone Foucault (Cfr. Ávila, 2017) o de preguntar por una "máquina" que genera cesuras al interior de

12 Véase: Benveniste (1983). 
la animalidad y humanidad "del hombre" (Agamben, 2006) ${ }^{13}$, es menester problematizar también el especismo y su producción del excepcionalismo humano ${ }^{14}$. Es necesario, entonces, tener en cuenta el papel que cumple la "especie" no sólo en la distribuciones diferenciales en virtud de la clase, el sexo/género o la raza, sino también en la naturalización del sacrificio de los cuerpos llamados "animales".

De este modo, la conexión oblicua entre los dispositivos de humanización, feminización, racialización, generización, animalización, etc., deben pensarse en el horizonte de un análisis interseccional del poder, comprometido con los vivientes no humanos, considerando a estos últimos como aquellos cuerpos cuyo sacrificio es un eje central para el circuito capitalista. A la par, desenmascarar lo humano como dispositivo de poder implica problematizar las distribuciones diferenciales sobre la vida que ubican a determinados cuerpos en posiciones de vulnerabilidad, redundando en vidas que pueden ser usufructuadas y devoradas para asegurar el sostenimiento de la comunidad política: cuerpos feminizados, racializados, con diversidad funcional, gays, lesbianas, entre otros.

Asimismo, es menester que la crítica posthumanista, que pone el acento en la crítica al ideal humanista de "hombre" como representante universal de lo humano (Braidotti, 2016), devenga una crítica a la jerarquización de las especies que apueste por una ecojusticia multiespecie, como indicaba Haraway.

\section{La ética del cuidado en clave deconstructiva posthumana}

Soy en mi casa el invitado de otro Jacques Derrida (2001, p. 50)

Si desde la deconstruccion se han indicado las conexiones oblicuas que se tejen entre subjetividad, masculinidad y soberanía para pensar las políticas de sujeción animal, en esta sección nos preguntamos por éticas y políticas del cuidado que no sigan considerando a los cuerpos animalizados y

${ }^{13}$ Para una perspectiva crítica de la cuestión animal en Giorgio Agamben remito a Ca$\operatorname{larco}(2007)$.

${ }^{14}$ Retomo la lectura crítica que realiza Iván Ávila de la biopolítica foucaulteana, al señalar que el Estado discrimina, divide y jerarquiza el gran continuo de la Naturaleza, y una de las primeras divisiones hechas es la de humano/animal. Véase: Ávila Gaitán (2017). 
feminizados como vidas desechables y mercantilizables de suyo ${ }^{15}$. Quizás en ello consista el reto más difícil para la llamada "cuestión de los animales", a saber, deconstruir la maquinaria carnofalogocéntrica de supresión de las vidas no humanas, a fin de pensar modos de ser-con que desplacen irreversiblemente al Hombre, en tanto invención normativa, del eje de la ética y la política.

Braidotti ha señalado que el Hombre es una ficción normativa a partir de la cual son jerarquizados los "Otros" producidos históricamente. En otros términos: el Hombre siempre ha sido una categoría negociable, pues todo aquél que difiere de la norma eurocéntrica, masculinizante y blanca es catalogado como "diferente de", lo cual significa estar situado en un lugar de subordinación. Esta es la razón por la cual la citada filósofa señala que "no todos podemos sostener, con cierto grado de seguridad, que hemos sido siempre humanos" (2015, p. 8). Si el Hombre/Sujeto es una categoría histórica e in-esencial, entonces es necesario mostrar la violencia ejercida contra los vivientes no humanos como una de las consecuencias más perniciosas en las que ha redundado el humanismo especista y falogocéntrico.

En efecto, la tesis del excepcionalismo humano ha sido funcional para la exclusión de aquellos existentes que no se corresponden con el ideal humano que tácitamente subyace a su aparente universalismo: siempre existieron gradaciones dentro de la categoría de lo humano según el sexo/género, la raza, la clase, etc. De este modo, "el «Hombre» no puede pretender representar a la humanidad" (Braidotti, 2016, p. 103) puesto que, lejos de ser universal, es una entidad marcada históricamente: es europeo, cisheterosexual, varón y blanco. El sujeto humano, en tanto ideal de normalidad, tiene a su reverso un ámbito de discontinuidad, de aquello que la filósofa Judith Butler llamó las “zonas de inhabitabilidad” (2002, p. 20), es decir, espacios de abyección que redundan en precariedad política y cultural. De allí que sea insoslayable patentizar el carácter ficticio e histórico del Hombre, operando de este modo una deconstrucción de sus ideales normativos, para así abrir el espacio a diversos modos de resistencias posibles.

Por otro lado, si el Hombre es una fábula normalizadora, la respuesta ético-política ante las lógicas sacrificiales no puede consistir en la búsqueda de igualdad o en la mera ampliación de la comunidad moral, pues esto significaría la simple re/producción de ese ideal humanista. La lógica sub-

${ }^{15}$ En otros términos: si la administración biopolítica de la vida ha sido cuestionada desde múltiples perspectivas, es necesario pensar otros modos de relación con los vivientes animales que no impliquen los dispositivos de la inferiorización, mercantilización y muerte. 
yacente al "enfoque de la identidad" (Calarco, 2016, p. 29) es la extensión del estado dominante, expresado en términos de "derechos", lo cual niega las diferencias entre los vivientes movilizando una ontología de lo Mismo; siempre se trata de lograr una igualación de lo inferior y subordinado con lo así considerado "superior". Pero ese enfoque sólo amplía los límites y exclusiones, quedando intacto el esquema jerárquico que extiende determinados privilegios. Igualmente, tal y como señala Braidotti recordando un artículo de Luce Irigaray, llamado "Egales à Qui?" (1987), si la igualdad significa la simple imitación de ese ideal humanista, entonces "la igualdad es demasiado banal como para constituir un objetivo político" (2016, p. 6). En efecto, al intentar ampliarse la comunidad ético-política, queda sin problematizar la fábula normativa llamada Hombre y, por tanto, el esquema sacrificial que caracteriza a nuestras prácticas y discursos hegemónicos.

Dado lo anterior, si los cuerpos que no responden al ideal normativo de lo humano aparecen como material usufructuable y, por ende, son considerados como formas de vida para usar y desechar, es menester responder desde una ética feminista del cuidado basada en la hospitalidad con los otros, sean humanos o no. Más aún, el tránsito hacia una ética del cuidado no puede residir en una búsqueda de la igualdad ${ }^{16}$, sino que debe consistir en una apuesta por modos de existir con los otros en la diferencia radical. Así pues, la muerte del Hombre (y con ello, la del Animal) ${ }^{17}$ abre paso a modos otros de pensar la comunidad en los que no hay una propiedad que delimite un espacio de lo común, sino la promesa de construir formas de vida desde las coordenadas de la otredad. Es necesario reflexionar, entonces, de qué manera los trabajos del cuidado pueden configurar alternativas a la máquina carno-falogocéntrica, al repensar los modos de coexistencia desde la hospitalidad, la cooperación y el cuidado mutuo.

En este sentido, si el "cuidado" supone un conjunto de actividades orientadas a proteger nuestros espacios vitales (Tronto, 1993), pensarlo sin una lógica homogeneizadora sino, antes bien, desde la afirmación de una alteridad radical e inapropiable, posibilitaría un desmantelamiento de aquellas políticas carnofalogocéntricas que privilegian determinadas vidas frente a otras. Por ende, una ética del cuidado pensada en clave hospitalaria permitiría radicalizar el cuestionamiento a las normas hegemónicas de pertenencia y de parentesco: el Estado, la familia y, por tanto, el lugar de nacimiento;

${ }^{16}$ Tal es el caso de Josephine Donovan quien piensa una ética del cuidado desde las coordenadas de la igualdad (2013).

${ }^{17}$ Cfr. Cavalieri (2009). 
pero además el género, la especie, la clase o la raza ${ }^{18}$. Sin embargo, ¿cómo es posible divisar éticas del cuidado allí donde el otro se resiste a la cómoda tranquilidad de la semejanza y el reconocimiento? ¿Cómo construir lo común en la diferencia, esto es, espacios hospitalarios de cuidado con el otro, sin que este sea apropiado por el esquema de la identidad-mismidad? "Decimos sí al recién llegado [arrivant], antes de cualquier anticipación, antes de cualquier determinación, antes de cualquier identificación" (Derrida, 2000, p. 82).

En una apuesta por una comunidad del respeto a la alteridad, la deconstrucción ha visibilizado que la tentativa de determinación del interior y el afuera de la comunidad es uno de los gestos más nocivos en la tradición occidental, ya que implica una reducción de la diferencia del Otro a una ontología de lo Mismo. En este sentido, el autor ha indicado el sueño dogmático de toda ética que permanece entre hombres, porque habilita un trato irresponsable, un sacrificio legítimo para con los seres que exceden este espacio (humano) de semejanza. Esta ética no considera que exista "crueldad" o "violencia" contra los animales y que la distinción entre lo justo y lo injusto tenga sentido respecto a ellos: los cuerpos animalizados pueden ser asesinados y sometidos sin ningún tipo de cuestionamiento. En palabras de Derrida:

Ahora bien, ¿acaso sólo se tiene deber hacia el hombre y hacia el otro como otro hombre? Y, sobre todo, ¿qué responder a aquellos que no reconocen en algunos hombres a sus semejantes? Esta pregunta no es abstracta, como ustedes saben. Todas las violencias, y las más crueles, y las más humanas, se han desencadenado contra seres vivos, bestias u hombres, $\mathrm{y}$ hombres en particular, a los que justamente no se les reconocía la dignidad de semejantes [...]. Un principio de ética o, más radicalmente, de justicia [...] es quizá la obligación que compromete mi responsabilidad con lo más desemejante, con lo radicalmente otro, justamente, con lo monstruosamente otro, con lo otro incognoscible. Lo «incognoscible» -diría yo de manera un tanto elíptica- es el comienzo de la ética, de la Ley, y no de lo humano. Mientras hay algo reconocible, y semejante, la ética dormita. Duerme un sueño dogmático. Mientras sigue siendo entre hombres, la ética sigue siendo dogmática, narcisista, y todavía no piensa. Ni siquiera piensa el hombre del que tanto habla (2010, p. 139).

La ética tiene lugar como radical cuestionamiento del sujeto, interpela al lugar de una alteridad que, en cuanto desapropiadora y desapropiante, es irreductible al imperio de lo Mismo. Si un principio de justicia compromete mi responsabilidad con lo otro incognoscible, debemos apostar por un impulso ético de cuidado para con el otro desde una responsabilidad infinita e

${ }^{18}$ Para este tema Véase: González, Ávila Gaitán y Gómez (2017). 
incalculable, que rompa con la lógica de homogeneización y el imperativo de reconocimiento basado en la idea de semejanza ${ }^{19}$. No se trata entonces de concebir a los existentes como iguales, sino de pensar un "vivir juntos" que desvanezca la excepcionalidad humana y cuestione el mero esquema de reciprocidad entre unos y otros. En breve: la declinación de lo humano trae consigo la promesa de reinvención de los modos de habitar lo común entre las diferentes formas-de-vida.

\section{Conclusiones}

Luego del recorrido propuesto nos interesa retomar algunos de los argumentos que hemos desplegado a lo largo del artículo. Nuestro objetivo principal era analizar las posibilidades de resistencia ético-políticas ante la "máquina carno-falogocentrica" en el marco de un abordaje cuyo eje sea la deconstrucción del binomio humano/animal.

Lo analizado permite comprender que una lectura en clave biopolítica de la noción de carno-falogocentrismo visibiliza las jerarquías diferenciales en la producción normativa de lo humano, la cual delimita las vidas a preservar-aquellas que responden a la norma humana, blanca, cisheterosexual, racional y masculina- y las vidas no meritorias de llanto: aquellas que son situadas en el horizonte de lo animal, justificando así su marginación y/o muerte. Por ese motivo, se sostuvo que las opresiones por clase, raza, sexo/ género u orientación sexual, entre otras, no pueden desvincularse de la jerarquía de especie. Dado que este enfoque interseccional es propuesto también por los ecofeminismos, nos pareció conveniente vincular algunos de sus aportes, particularmente la noción de "política sexual de la carne" de Carol Adams, con la nociones derridianas de "carno-falogocentrismo" y de "virilidad carnívora". En este trayecto hallamos la necesidad de establecer nexos transversales entre las diversas subordinaciones sexuales, raciales, de clase y de especie, conexiones que las posturas ecofeministas han ubicado en una "lógica de dominación global", dado que son funcionales al orden de poder identificado por Haraway como el "patriarcado capitalista blanco".

Para concluir, el interrogante ineludible parece ser aquel que pregunta sobre las posibilidades de un habitar comunitario una vez deconstruidas las normas hegemónicas de lo humano. Creemos que una ética del cuidado

\footnotetext{
${ }^{19}$ Véase: González (2016).
} 
pensada en clave hospitalaria convocaría a un proceso de desplazamiento de los dispositivos normativos y homogeneizantes que organizan las formas-de-vida, esto es, conduciría a interrogar por el modo en que determinadas existencias son producidas como vidas más dignas de vivirse, frente a aquellas otras que son arrojadas a zonas de inhabitabilidad según un dualismo jerarquizante. Si se patentizara el carácter político (y, por tanto, contingente e histórico) de conceptos pretendidamente "naturales" como lo humano y lo animal, al tiempo que se operara una crítica interseccional de la lógica carnofalogocéntrica, quizá fuese posible apostar por espacios de coexistencia alternativos, por nuevos (y provisorios) mundos que, desde los márgenes, se atrevan a configurar modalidades de vida en común hospitalarias, sustentables y en continuo devenir, capaces de oponerse a los dispositivos humanistas de explotación, subordinación y sujeción.

\section{Bibliografía}

Adams, C. (2016) La política sexual de la carne. Una teoría crítica feminista vegetariana, Madrid, ochodoscuatro ediciones.

Adams, C. (2017) "Proteína feminizada: significado, representaciones e implicancias", en Andreatta, M. M.; Pezzetta, S.; Rincón, E. (Eds.). Crítica $y$ animalidad: cuando el otro aúlla, La Plata, ELECA, pp. 72-97.

Agamben, G. (2006) Lo abierto. El hombre y el animal. Buenos Aires, Adriana Hidalgo.

Ávila Gaitán, I. (2016) La cuestión animal(ista), Bogotá, Ediciones Desde Abajo.

Ávila, Gaitán, I. (2017) Rebelión en la granja. Biopolítica, Zootecnia y Domesticación, Bogotá, Ediciones Desde Abajo.

Benveniste, É. (1983) Vocabulario de las instituciones indoeuropeas, Madrid, Taurus.

Braidotti, R. (1991) Patterns of Dissonance: A Study of Women in Contemporary Philosophy, Nueva York, Routledge.

Braidotti, R. (2005) Metamorfosis. Hacia una teoría materialista del devenir, Madrid, Akal.

Braidotti, R. (2009) Transposiciones. Sobre la ética nómada. Barcelona, Gedisa.

Braidotti, R. (2015) Lo posthumano, Barcelona, Gedisa.

Braidotti, R. (2016) "Lo posthumano no es enemigo de lo humano" Entrevista realizada por Eva Muñoz, Revista de Occidente, Madrid, $N^{\circ}$ 426, pp. 101-114. 
Butler, J. (2002) Cuerpos que importan: sobre los limites materiales y discursivos del "sexo", Buenos Aires, Paidós.

Calarco, M. (2007) "Jamming the Anthropological Machine", En: Matthew C.; Steven D. (Eds.) Giorgio Agamben: Sovereignty and Life, Stanford, CA, Stanford University Press, pp. 163-179.

Calarco, M. (2016) "Identidad, diferencia, indistinción”, Revista Latinoamericana de Estudios Críticos Animales, La Plata, Año III Vol. I, pp. 27-49.

Cavalieri, P. (2009). The death of the animal: a dialogue on perfectionism. New York: Columbia University Press. https://doi.org/10.7312/ cava14544

Cixous, H. (1995) La risa de la medusa, Barcelona, Anthropos.

Cragnolini, M. (2012) "Virilidad carnívora: el ejercicio de la autoridad sojuzgante frente a lo viviente", Revista Científica de UCES, Buenos Aires, vol. XVI, n 1 , pp. 23-29.

Cragnolini, M. (2013) "Ecce animot o del quién al qué. Tránsitos derridianos hacia la comunidad de los vivientes". En: Cragnolini, M. B. (Ed.), Entre Nietzsche y Derrida: vida, sobrevida, muerte, Lanús, La Cebra, pp. 357-378.

Deleuze, G. \& Guattari, F. (2012). Mil mesetas Capitalismo y esquizofrenia. Valencia, Pretextos.

Derrida, J. (1989) Entrevista de Cristina de Peretti, Política y Sociedad, Madrid, 3, pp. 101-106.

Derrida, J. (2000) La hospitalidad, Buenos Aires, Ediciones de la Flor.

Derrida, J. (2001) ¡Palabra!. Instantáneas filosóficas, Madrid, Trotta.

Derrida, J. (2005) “'Hay que comer' o el cálculo del sujeto”, entrevistado por J-L. Nancy, Pensamiento de los confines, Buenos Aires, Fondo de Cultura Económica, N 17, pp. 151-170.

Derrida, J. (2008a) El animal que luego estoy si(gui)endo, Madrid, Trotta. Derrida, J. (2008b) De la gramatología, Buenos Aires, Siglo XXI.

Derrida, J. (2010) Seminario La bestia y el soberano, volumen I, Buenos Aires, Manantial.

Donovan, J. (2013) "The Voice of Animals: A Response to Recent French Care Theory in Animal Ethics". Journal for Critical Animal Studies, Volume 11 Issue 1, pp. 8-23.

Fleisner, P. (2017) "Vida de perros: entre literatura infantil y filosofía de la animalidad". Literatura: teoría, historia, crítica, Bogotá, 19.1, pp. 111138.

Foucault, M. (2005) Historia de la sexualidad. I. La voluntad de saber, Madrid, Siglo XXI. 
Foucault, M. (2008). Defender la sociedad. Curso en el Collège de France (1975-1976). México, Fondo de Cultura Económica.

Giorgi, G. (2017) "La pregunta por el animal. Dos historias" en Navarro, A.; González, A. (Eds.) Es tiempo de coexistir: perspectivas, debates y otras provocaciones en torno a los animales no bumanos, La Plata, ELECA, pp. 9-14.

González, A. G. (2016) "Una lectura deconstructiva del régimen carnofalogocéntrico: hacia una ética animal de la diferencia”, Daimon. Revista Internacional de Filosofía; Universidad de Murcia, n69, pp. 125-139.

González, A. G.; Ávila Gaitán, I; Gómez, J. (2017), “Devenires del cuidado: materialismo inmanente, afecto y hospitalidad" en: Navarro, A.; González, A. G. (Ed.), Es tiempo de coexistir: Perspectivas, debates y otras provocaciones en torno a los animales no humanos, La Plata, ELECA, 2017, pp. 146-159

González-Marín, C. (1986) “Jacques Derrida: leer lo ilegible”, Revista de Occidente, Madrid, 62-63, pp. 160-182.

Haraway, D. (1995) Ciencia, cyborgs y mujeres. La reinvención de la naturaleza, Madrid, Cátedra.

Haraway, D. (2016) “Antropoceno, Capitaloceno, Plantacionoceno, Chthuluceno: generando relaciones de parentesco", Revista Latinoamericana de Estudios Críticos Animales, La Plata, Año III Vol. 1, pp. 15-26.

Irigaray, L. (1987) "Egales à Qui ? ", Critique. Revue Générale des Publications françaises et étrangères, 43 480, pp. 420-437.

López, C. (2008) "Matar callando: el revés de la trama biopolítica", presentado en las V Jornadas internacionales de ética "No matarás" organizadas por Escuela de Filosofía de la Universidad de Salamanca, agosto de 2008. Recuperado de: http://www.usal.edu.ar/archivos/fyl/otros/ no_mataras.pdf

Plumwood, Val (1993) Feminism and the Mastery of Nature, London, Routledge.

Preciado, P. (2014) "El feminismo no es un humanismo", publicado en $\mathrm{Li}$ bération. Recuperado de: http://paroledequeer.blogspot.fr/2014/10/elfeminismo-no-es-humanismo-por.html

Rodríguez, Magda R. M. (2004) Foucault y la genealogía de los sexos, Barcelona, Anthropos.

Shukin, N. (2009) Animal Capital. Rendering Life in Biopolitical Times, Minneapolis, University of Minnesota Press.

Tronto, J. (1993). Moral Boundaries: a political argument for an ethical of care, New York, Routledge. 
Wadiwel, D. (2002) "Cows and Sovereignty: Biopower and Animal Life",

Borderlands, volume. Recuperado de: http://www.borderlands.net.au/ vol1no2_2002/wadiwel_cows.html

Warren, K. (2003), Filosofías ecofeministas, Barcelona, Icaria. 